\title{
Article \\ Embodied Energy in Pyrolysis and Solvolysis Approaches to Recycling for Carbon Fiber-Epoxy Reinforced Composite Waste Streams
}

\author{
Komal Kooduvalli ${ }^{1,2,3}$, John Unser ${ }^{2}$ (D), Soydan Ozcan ${ }^{2,3}$ and Uday K. Vaidya ${ }^{1,2,3, *}$ \\ 1 Fibers and Composites Manufacturing Facility, The University of Tennessee, 1321 White Ave, \\ Knoxville, TN 37996, USA; kkoodva@utk.edu \\ 2 Institute for Advanced Composites Manufacturing Innovation (IACMI), 2360 Cherahala Blvd, \\ Knoxville, TN 37932, USA; junser@iacmi.org (J.U.); ozcans@ornl.gov (S.O.) \\ 3 Oak Ridge National Laboratory, Manufacturing Sciences Division, 1 Bethel Valley Rd, \\ Oak Ridge, TN 37831, USA \\ * Correspondence: uvaidya@utk.edu
}

check for updates

Citation: Kooduvalli, K.; Unser, J.; Ozcan, S.; Vaidya, U.K. Embodied Energy in Pyrolysis and Solvolysis Approaches to Recycling for Carbon Fiber-Epoxy Reinforced Composite Waste Streams. Recycling 2022, 7, 6. https: / / doi.org/10.3390/ recycling7010006

Academic Editors: Michele John and Wan-Ting (Grace) Chen

Received: 30 May 2021

Accepted: 9 February 2022

Published: 14 February 2022

Publisher's Note: MDPI stays neutral with regard to jurisdictional claims in published maps and institutional affiliations.

Copyright: (C) 2022 by the authors. Licensee MDPI, Basel, Switzerland. This article is an open access article distributed under the terms and conditions of the Creative Commons Attribution (CC BY) license (https:// creativecommons.org/licenses/by/ $4.0 /)$.

\begin{abstract}
Carbon fiber composites are increasingly used in aerospace, motorcycles, sporting, and high-performance vehicles, and their end of life recycling is of growing interest. This study deals with the life cycle assessment (LCA) of carbon fiber reinforced plastics (CFRP) waste streams. The embodied energy (EE) of recycling CFRP via two viable methods-i.e., pyrolysis and solvolysis-is studied. Both pyrolysis and solvolysis were studied for EE with different variants. Alongside fiber recovery from CFRP, the pyrolysis process calculations consider energy recovery from syngas and oil produced within the system. For pyrolysis, electric furnace and natural gas were primarily considered. For solvolysis, different solvent scenarios were considered, including (a) deionized water, (b) water and potassium hydroxide, (c) acetone and water, and (d) water with acetic acid and potassium hydroxide. Energy reduction from one generation to the next has also been highlighted. The EE for recycling CFRP is quantified and discussed for these scenarios in this paper.
\end{abstract}

Keywords: recycling; composites; embodied energy; pyrolysis; solvolysis; life cycle assessment

\section{Introduction}

Millions of kilograms of composites are increasingly used in marine vessels, wind turbine blades, bridge construction, automotive, aircraft, rail, and trucks. While composites help reduce weight and energy consumption during use, their end of life is largely in the form of landfill and less established recycling/reuse. Technology advancements in recycling of composites will drive innovative products at reduced energy and cost. A large portion of the composite properties are dominated by the reinforcement. To this end, pyrolysis and solvolysis are considered as leading recycling technologies to recover the reinforcing fiber such as glass, carbon, aramid, and hybrid fibers in thermoset composites.

Space limitations both at local and international scales due to waste disposal bans are displacing roughly 111 million metric tons of plastic (unreinforced) trash. This will only be compounded by the global rising demand for carbon fiber (CF) and composites [1,2]. However, this provides the opportunity for creating a circular economy for carbon fiber reinforced polymer (CFRP) composite products. For example, it has been reported that the energy consumption required to manufacture recycled CF (rCF) is merely $5-10 \%$ of the energy required to produce virgin $\mathrm{CF}(\mathrm{vCF})[2]$.

In the case of the aerospace industry, it is estimated that by the year 2025, 8500 planes will be decommissioned, which roughly translates to 154,221 tons of CF that could potentially be diverted away from landfill and given a second life through recycling [3,4]. With growing demand for CF estimated to reach 116,000 tons by 2021 , the recycled carbon fiber (rCF) market can channel the potential to assist the market with supply for this demand [5]. 
This aligns with two of the principles of circular economy, which (a) aim to reduce the amount of waste entering landfills, and (b) prolong the life of a product through reuse and recycling methods [6]. By categorizing recycling technologies under those specified by Pimenta, S and Pinho, S.T. [7], the initial steps in this work related to size reduction relate to mechanical recycling (shredding, sorting). The current work focuses on two recycling processes, namely pyrolysis and solvolysis. Pyrolysis is classified as a thermal process with capability for energy recovery [8]. Solvolysis, a chemical process capable of fiber recovery and resin reuse $[9,10]$. These are now briefly explained.

\subsection{Pyrolysis Process}

Pyrolysis employs a technique wherein CF-epoxy composites are heated to high temperature (in the range between $350-800^{\circ} \mathrm{C}$ ) in the absence of oxygen (to avoid charring) in inert atmospheres (such as nitrogen) in order to break down the composite into gas, oil, and fiber constituents [8]. Figure 1 provides a schematic of the pyrolysis furnace including the sorting process, until the remanufacturing step in the second generation, and composite waste reduction in downstream processes. Transportation, size reduction and post processing steps were added to represent a complete system. This approach was then used as a basis for building the model in the life cycle analysis (LCA) software.

Initially, the CF-epoxy laminate undergoes size reduction with primary and secondary shredding steps. The feedstock is then fed into a furnace with temperatures ranging from 350 to $800{ }^{\circ} \mathrm{C}$. Our model considers a continuous operation to process (1.7 metric tons) 3800 pounds every $1.25 \mathrm{~h}$. This has potential to run at a frequency that recycles 1200 metric tons of carbon fiber per year [11]. Further, in pyrolysis, the gas particles pass through the abatement system or scrubber where they are recirculated within the system to be used as an alternative fuel. The hot gases condense to form oil within the hydrocracking system. The post-processing of recycled carbon fiber can follow number of routes [12]. In this work, the post-recycle conversion into intermediate mats was assumed. The combing and carding were assumed as the processes for obtaining the recycled mats, considering a throughput of $13,607 \mathrm{~kg}(30,000$ pounds) per hour.

\subsection{Solvolysis Process}

Solvolysis is a chemical process that is applied at low (subcritical) or high (supercritical) temperatures [9]. Solvolysis acts on the composite at supercritical temperature and pressure (conducted at $375-650{ }^{\circ} \mathrm{C}$ ranging between $22-35 \mathrm{MPa}$ [12] of the solvent. A catalyst decreases operation time [9] to dissolve the resin and recover the fiber for remanufacture. Solvolysis can also be conducted without a catalyst [10]. Studies have shown that the tensile strength and modulus of single fiber filaments can be retained to $100 \%$ of virgin properties [10,13]. For this paper, the supercritical solvolysis process with a batch-type reactor is considered.

The solvolysis process route is explained in Figure 2. The process begins with primary and secondary shredding and transportation (same as the previous pyrolysis values) to the reactor where supercritical temperature and pressures act upon the end of life (EOL) composite matrix. The resultant constituents include the recovered carbon fibers and organic compounds during resin degradation. 

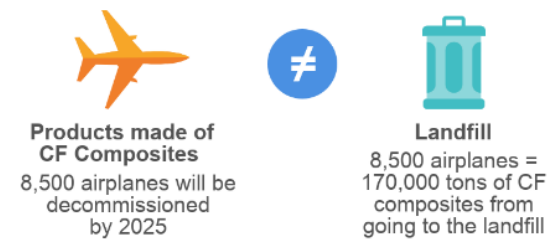

Here is how we are changing the story using pyrolysis to recycle carbon fiber composites.
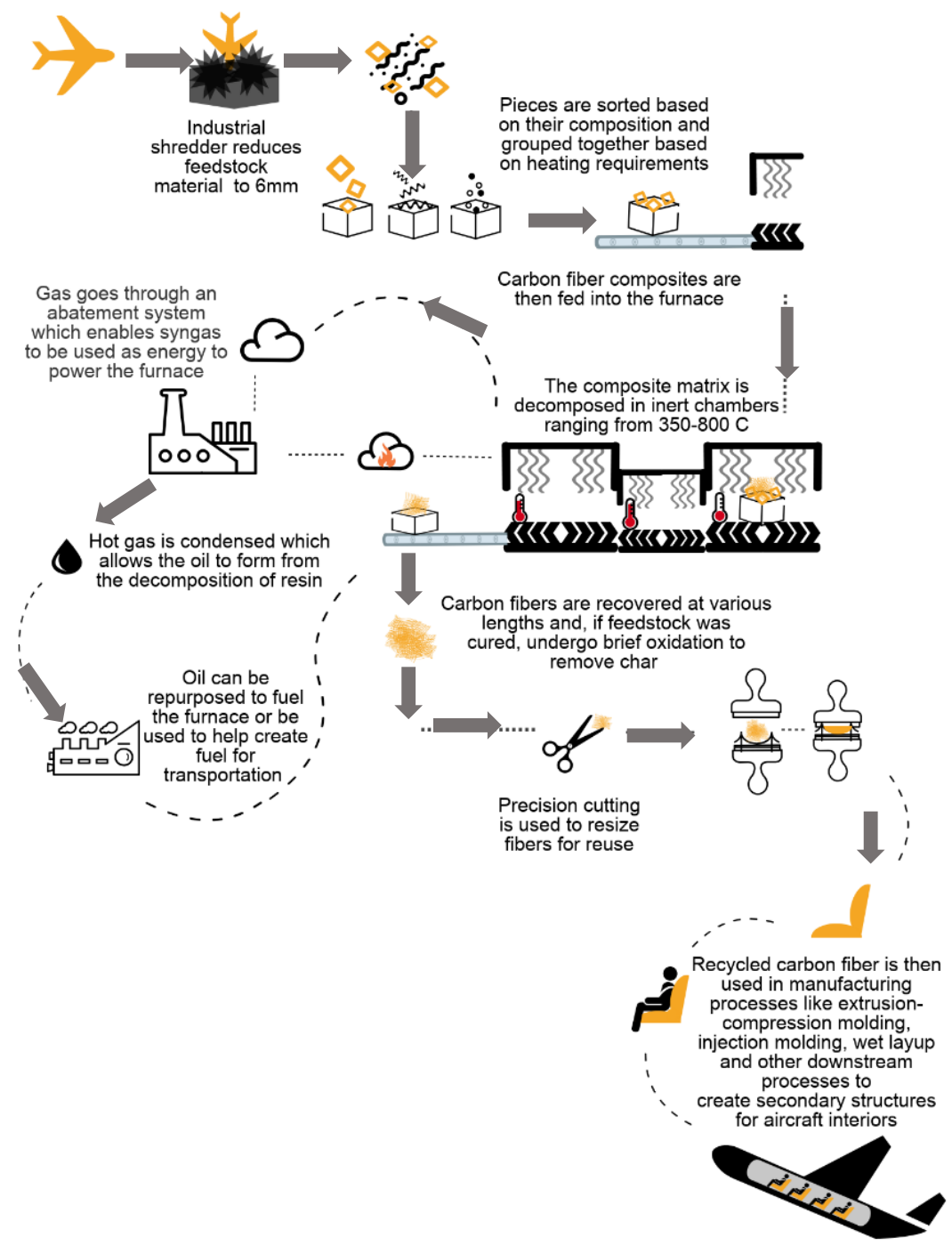

Figure 1. The pyrolysis process when applied to aerospace CFRP to promote circularity.

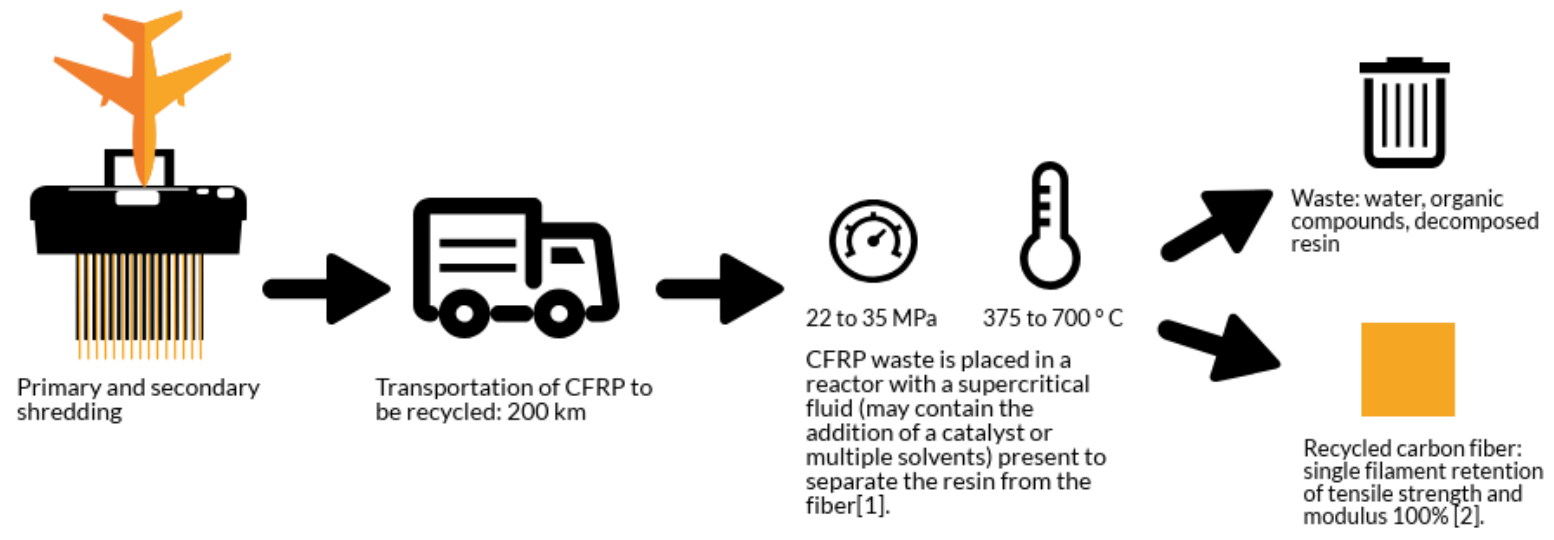

Figure 2. The solvolysis process when applied to aerospace CFRP EOL parts. 


\section{Scope of the Current Study}

The CFRP recycling technology scenarios considered in this paper build on a previous study by the authors, in relation to pyrolysis and solvolysis technologies. [11]. Prior work considered a $1 \mathrm{~kg}$ CF-epoxy composite laminate as the benchmark specimen. The embodied energy (EE) with respect to a natural gas-based pyrolysis system and a supercritical solvolysis system utilizing water as its primary solvent was studied. Energy impacts were reported alongside each processing step.

In the case of the pyrolysis system, the analysis included the energy that was recovered by pyrolyzing the resin as (a) syngas, to run the operation as 'avoided energy' (energy offset to be used in the place of conventional fuel), and (b) the base case which consists of the pyrolysis process without considering any form of avoided energy. The solvolysis process considered a batch-type supercritical reactor using deionized water as solvent to evaluate the EE of the same $1 \mathrm{~kg}$ CF-epoxy specimen.

This paper explores the EE contained per step of both pyrolysis and solvolysis processes with additional scenarios considered. Various pyrolysis furnace systems such as (a) electric, (b) electric with renewable (solar) energy, and (c) natural gas are considered. Energy reduction due to reuse of syngas produced during burning and reuse of oil from the hydrocracker are included for all three furnace types. With respect to solvolysis, solvents related to the supercritical process have been considered. Additionally, the overall reduction in EE from one generation to the next is demonstrated using the cut-off approach $[12,13]$. This helps determine the change in EE within the product from one generation to the next.

\section{Materials and Methods}

Life cycle analysis (LCA) is a technique to quantify the environmental impacts associated with a product, process, or services' life cycle by including all the stages of its supply chain from raw material extraction, to transportation, manufacturing, use phase, and end-of-life [14].

Carbon/epoxy is considered as the source material system for pyrolysis and solvolysis in this study. These are representative of materials obtained from out-of-date carbon/epoxy prepregs, decommissioned aircraft, racing cars and sporting goods such as bicycles and hockey sticks. The pre-pregs typically comprise $62 \%$ volume fraction carbon fibers in high performance epoxy resin, typically $250^{\circ} \mathrm{F}$ or $350^{\circ} \mathrm{F}$ cure. In this work, we consider pre-preg as a family of material systems and not from a specific vendor.

A single-issue method which focuses on understanding the energy that the supply chain embodies (including those of primary energy sources) is known as EE $[15,16]$. A gateto-gate system boundary was outlined for both pyrolysis and solvolysis recycling technologies. This was then expanded to include a cradle-to-grave (with two generations) analysis for the $1 \mathrm{~kg}$ CF-epoxy laminates, following the ISO 14040 and 14044 standards $[17,18]$.

A hybrid data collection approach entailed (a) industry and academic survey from partner institutions, (b) equipment specification(s), and (c) background data referencing literature review. LCA software datasets, namely, Ecoinvent 3.4 (using allocation, cut-off by classification unit) [19,20], ELCD v3.2 [21,22], and US-EI 2.2 [23]) were employed for the model. SimaPro software [24] and the FRPC Energy Estimator Tool [25] was used to build the current model and analyze the LCA results.

The cumulative energy demand (CED) methodology $[26,27]$ was used to understand the EE value at each stage. The steps considered for LCA remain identical to [11]. These steps include primary shredding, secondary shredding, sorting, furnace, scrubber, hydrocarbon cracker, combing, precision cutting, and transportation.

The manufacturing process includes wet layup followed by compression molding for both fibers, i.e., produced by pyrolysis and solvolysis. Consistency is maintained for both generations of composites undergoing pyrolysis and solvolysis to ensure comparability. Landfilling is applied for both scenarios at the end of the second generation. For the second life cycle, energy from Life 1 recycling in terms of size reduction, pyrolysis/solvolysis, and post-processing is valued. This is then considered in Life 2 raw material ("refurbished") 
category on account of the assumption being that $100 \%$ recycled carbon fiber is to be utilized. Therefore, the cut-off approach (explained under Section 3) dictates that this refurbished material represents the recycled value in terms of the amount of recycled material used in Life 2 [28,29].

\section{Solvolysis Solvent Selection}

Four different scenarios of solvent usage were chosen for analysis. Scenario 1 followed the work of Khalil, in which a functional unit of $1 \mathrm{~kg}$ CFRP waste was analyzed with $4.67 \mathrm{~kg}$ of water and $0.131 \mathrm{~kg}$ of the catalyst potassium hydroxide as the solvent [30]. Scenario 2 followed the thesis of Sokoli [31] in which $7 \mathrm{~kg}$ of CFRP waste was analyzed with $7.5 \mathrm{~kg}$ of acetone and $15 \mathrm{~L}$ of water as the solvent. Scenario 3 followed the work of Meng, in which a functional unit of $1 \mathrm{~kg}$ of CFRP was analyzed with $0.45 \mathrm{~kg}$ of acetic acid, $1.35 \mathrm{~kg}$ of water, and $0.04 \mathrm{~kg}$ of the catalyst Sodium Hydroxide as the solvent [32]. Scenario 4 followed the thesis work of Knight, where $150 \mathrm{~kg}$ of CFRP was analyzed with $700 \mathrm{~kg}$ of water as the solvent [10]. Table 1 summarizes nine scenarios considered to understand the pyrolysis based EE values for CF-epoxy composites.

Table 1. Nine scenarios representing various pyrolysis cases considered for this study.

\begin{tabular}{cr}
\hline Scenario & Case Study Description \\
\hline Scenario 1A & Electric furnace with avoided energy from oil and syngas \\
Scenario 2A & Electric furnace without any avoided energy \\
Scenario 3A & Electric furnace without avoided energy from oil \\
Scenario 1B & Natural gas furnace with avoided energy from oil and syngas \\
Scenario 2B & Natural gas without any avoided energy \\
Scenario 3B & Natural gas without avoided energy from oil \\
Scenario 1C & Electric furnace utilizing renewable energy (purchased solar power) with \\
Scenario 2C & Electric furnace utilizing renewable energy (solar) without any avoided energy \\
Scenario 3C & Solar without avoided energy from oil. \\
\hline
\end{tabular}

Here, Scenarios 3A and 3B are found to be most prevalent within the industry currently compared to the others. The carbon fiber to epoxy ratio for each scenario is as follows: 60:40, 50:50, 55:45, and 65:35, based on the literature [10]. Each scenario was scaled to represent a functional unit of $1 \mathrm{~kg}$ CFRP epoxy with a 50:50 ratio of carbon fiber to epoxy, which is shown in the Supplemental Information.

\section{Pyrolysis: Assumptions and Estimations}

Several assumptions were made due to the sensitive and proprietary nature of the information relating to the pyrolysis furnace design and company innovations. These assumptions are listed below [11].

1. Epoxy breaks down into oil and gas in the furnace, with exact ratios taken from a laboratory study that used a small static bed reactor running at $600{ }^{\circ} \mathrm{C}$. These were then extrapolated to industry scale [33-36].

2. Environmental impacts of individual gases formed from the epoxy breakdown were not considered due to their containment and reuse within the system.

3. Regarding post-processing of recycled $\mathrm{CF}$, combing and carding were calculated based on industry information considering a throughput of $1360 \mathrm{~kg} / \mathrm{h}(3000 \mathrm{lb} / \mathrm{h})$.

4. Scrubber values were based on a standard cyclone design recommended by the Environmental Protection Agency [37,38].

5. For furnace systems that had the ability to reuse oil, data from hydrocrackers were taken; however, any catalytic system with the ability to break apart oil molecules could theoretically be used.

6. In order to obtain syngas densities, temperatures taken for individual chemical densities ranged from 500 to $600{ }^{\circ} \mathrm{C}$. 
7. Since power ratings of reactors were not available from the literature review, Knight's scaled-up industrial sized reactor with a $1.93 \mathrm{~m}^{3}$ volume was considered [10] as a basis for the temperature and pressure of supercritical solvents required for these cases. For this purpose, this study considers a reactor of $2 \mathrm{~m}^{3}$.

8. $200 \mathrm{~km}$ is the average distance taken for the overall transportation operation from one facility to another.

9. Power ratings of reactors were not provided for the industrial scale that was desired. Ultimately, a high pressure reactor that could maintain the required temperature and pressure of supercritical water and a volume of $2 \mathrm{~m}^{3}$ was chosen [39]. These properties are based on [10] where an industrial sized reactor was defined as $1.93 \mathrm{~m}^{3}$. This assumption was made due to lack of information regarding specifications for multiple solvent mixtures as well as solvent and catalyst mixtures.

10. Average distance of $200 \mathrm{~km}$ was considered for transportation of the CFRP waste. Some studies state that the solvent after solvolysis may be reused [31]. However, this was not considered in this study as the pathway of such processes was not clearly specified.

\section{Cut-Off by Classification Recycling Approach}

The cut-off by classification recycling approach [12,13,28,29] was applied to distinguish how energy values are split between the two generations of CF-epoxy laminates postrecycling as allocation is a key issue in LCA. Key takeaways from the cut-off approach are: (1) the recycler is rewarded for the amount of EOL waste recycled in that life (meaning, this energy is not considered in Life 1); (2) landfilling is always considered a burden, irrespective of the life it occurs in (energy is counted); (3) refurbished material used in post-recycled lives take up the value of recycling that was earlier not counted, based on the ratio that is used in place of the virgin material; (4) virgin burdens are always accounted for in all lives.

Therefore, Life 1 considers the burden of using carbon fiber and epoxy virgin materials and accounts for the energy related to the wet layup process at the facility, i.e., steps involved in creating the first-generation product. Next, shredding, in addition to the respective recycling technology, is rewarded and not accounted for under Life 1.

Starting raw materials in Life 2 being 100\% recycled material avoids the use of virgin materials and transportation (accounted for in Life 1). This way, the refurbished (starting material used in Life 2) material considers the Life 1 recycling energy for this amount, since $100 \%$ of the raw material taken is recycled, with no virgin materials used. The generation products are discarded to landfill, with Life 2 taking all the burden for disposal.

\section{Results and Discussion}

The following sections explain the results extracted from the LCA with respect to individual process cases as well as overall EE reduction from the first to second generation.

\subsection{Composite Recycling Impacts of Pyrolysis}

Table 2 summarizes the total EE associated with each step and variants. The most energy intensive step in the pyrolysis process was found to be that of the pyrolysis furnace, with transportation, size reduction, and post-processing steps accounting for a mere $1.168 \mathrm{MJ} / \mathrm{kg}$ of the total EE [11]. In addition to the natural gas furnace, the electric based pyrolysis furnace as well as electric with renewable energy offset was also considered. The EE of the pyrolysis furnace system including values for sorting, furnace type, scrubber, and (for those furnaces capable of processing oil) hydrocracker values were combined from Table 2. 
Table 2. Total EE per step within the pyrolysis process.

\begin{tabular}{cc}
\hline Step & MJ/kg \\
\hline Primary Shredding & 0.1649 \\
Secondary Shredding & 0.4361 \\
Sorting & 0.2695 \\
Electric Furnace & 125.14 \\
Natural Gas Furnace & 50.55 \\
Scrubber with reuse of gas & -9.695 \\
Scrubber without reuse & 0.0000007 \\
Hydrocracker with reuse of oil & -34.09 \\
Hydrocracker without reuse & 0.1916 \\
Combing & 0.000065 \\
Cutting & 0.000043 \\
\hline
\end{tabular}

A sensitivity analysis was run based on the ability of the furnace to reuse oil and gas to offset energy needed for heating the system. The most advanced pyrolysis process can avoid energy consumption by using the syngas and oil produced to power the same system. From Figure 3, the EE of recycling carbon/epoxy with the electric furnace was $81.63 \mathrm{MJ} / \mathrm{kg}$, while natural gas was only $7.04 \mathrm{MJ} / \mathrm{kg}$. The most energy-intensive scenario was a pyrolysis furnace where neither gas nor oil were reused to power the process. In these cases, an EE of $125.6 \mathrm{MJ} / \mathrm{kg}$ for electric and $51.02 \mathrm{MJ} / \mathrm{kg}$ for natural gas was estimated. However, the most common system found that is used in industry today is a pyrolysis furnace with capacity to capture and reuse the gas (excluding oil) created to power the same furnace. This has an estimated EE of $115.91 \mathrm{MJ} / \mathrm{kg}$ for electric and $41.32 \mathrm{MJ} / \mathrm{kg}$ for natural gas.

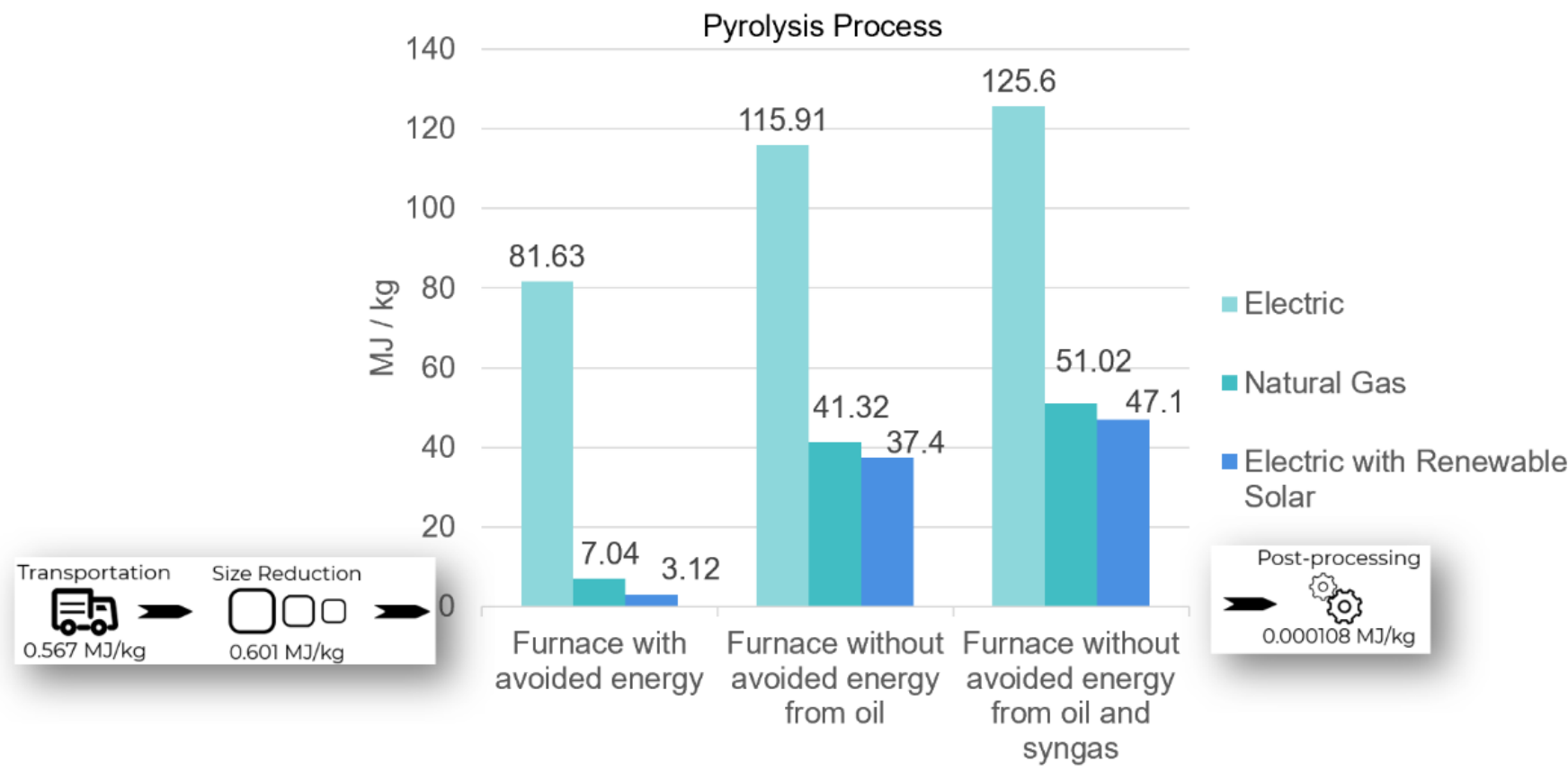

Figure 3. EE by scenario for recycling carbon fiber epoxy laminate via pyrolysis.

In all scenarios, natural gas furnaces were the least energy intensive option until electric furnaces powered by renewable solar energy were considered. Another sensitivity test revealed that renewable energy purchased to offset electricity consumed by electric furnaces outperformed the other options with an EE of $47.1 \mathrm{MJ} / \mathrm{kg}$ for no reuse, $37.4 \mathrm{MJ} / \mathrm{kg}$ for only gas reuse, and $3.12 \mathrm{MJ} / \mathrm{kg}$ for both gas and oil reuse.

While comparing the total EE between life cycles 1 and 2 for the selected 3A (electric furnace without avoided oil) (Figure 4a) and 3B (natural gas furnace without avoided oil) scenarios, the results (Figure $4 \mathrm{~b}$ ) show a significant decrease in EE. Scenario 3A exhibited a 
$68.5 \%$ decrease in EE from Life 1 to Life 2. Scenario 3B displayed an even more dramatic trend with a $79.6 \%$ decrease between cycles.

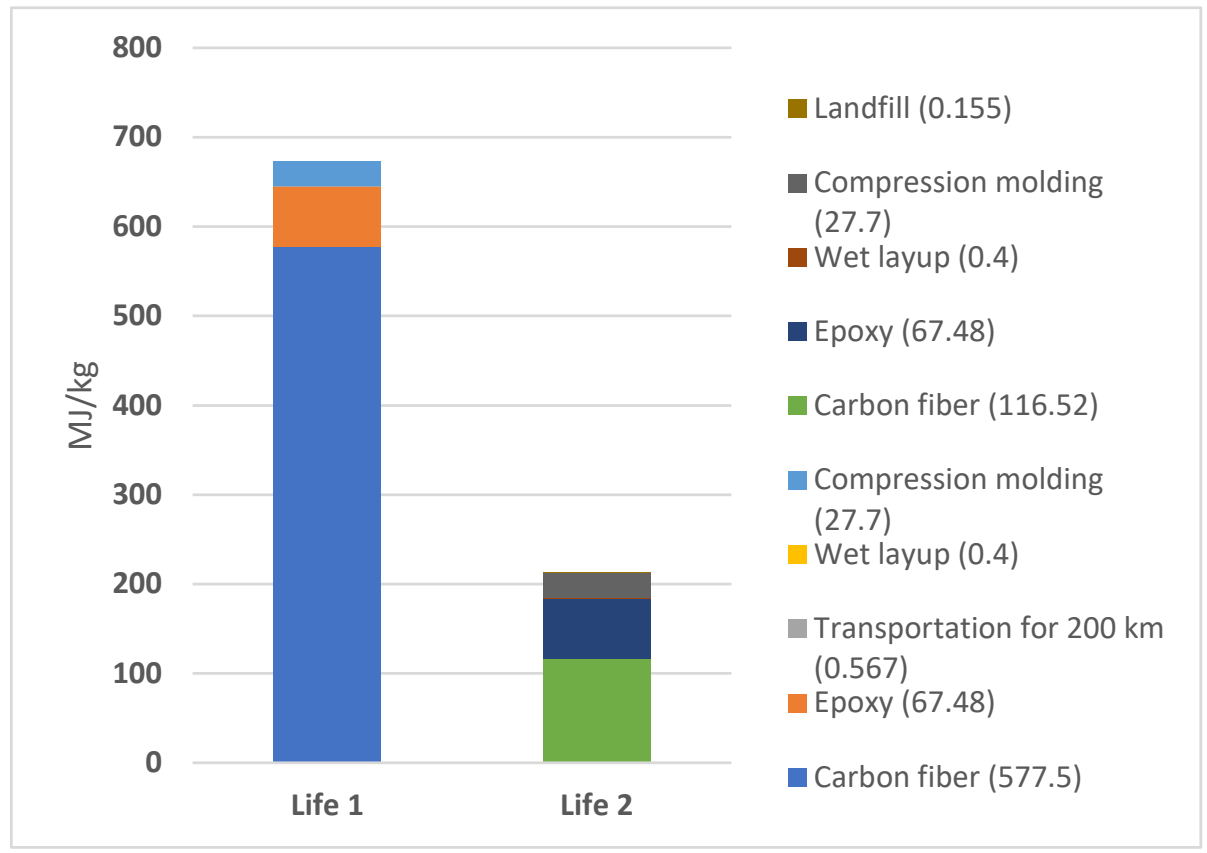

(a)

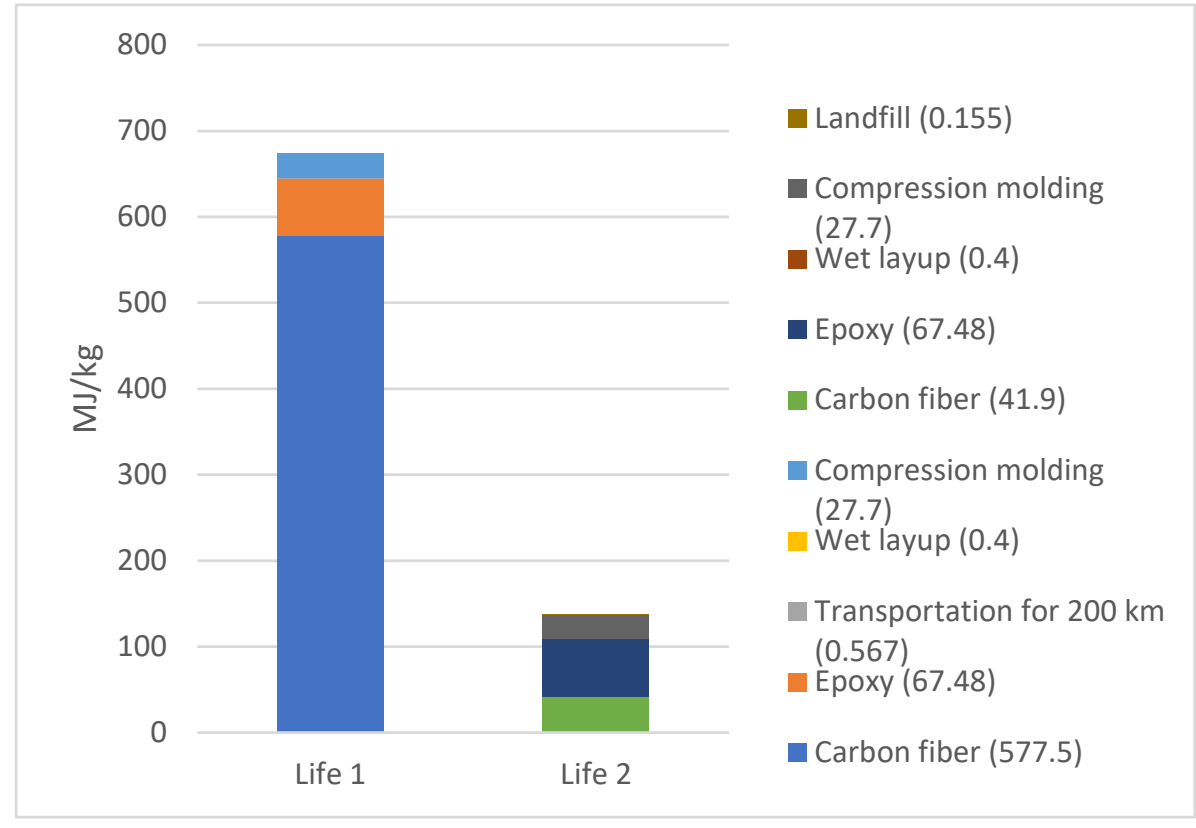

(b)

Figure 4. (a) Scenario 3a. EE comparison of Life 1 versus Life 2 for electric furnace scenario for pyrolysis; (b) Scenario 3B: EE comparison of Life 1 versus Life 2 for natural gas furnace scenario for pyrolysis.

More information regarding the exported values for each of these steps may be found in the supplementary data files. The primary peak in EE for Life 1 in both materials arise from the raw material sourcing for $\mathrm{CF}$, followed by the raw material sourcing of the epoxy resin and compression molding process. However, the largest EE values in Life 2 differ in both scenarios. For scenario $3 \mathrm{~A}, \mathrm{CF}$ raw material sourcing remains the largest contributor to the overall EE. For scenario 3B, epoxy raw material sourcing becomes the largest source 
of EE for the composite product. This difference is likely due to the variation in furnace type, with natural gas furnace requiring less energy than an electric furnace.

\subsection{Recycling Impacts of Solvolysis}

Figure 5 outlines the breakup of the process for solvolysis of the four scenarios outlined in Section 3. EE values of transportation, size reduction, and post-processing is shown in Table 3 . The highest EE is from transportation cost $(0.567 \mathrm{MJ} / \mathrm{kg})$ followed by secondary shredding $(0.44 \mathrm{MJ} / \mathrm{kg})$. Interestingly, the EE from primary shredding is $0.16 \mathrm{MJ} / \mathrm{kg}, \sim 63 \%$ lower than secondary shredding. This is attributed to primary shredding reducing the bulk to largerc, for which secondary shredding is more time consuming and involved greater interaction with the shredding blades. Combing and precision cutting have negligible EE in comparison to transportation and shredding.

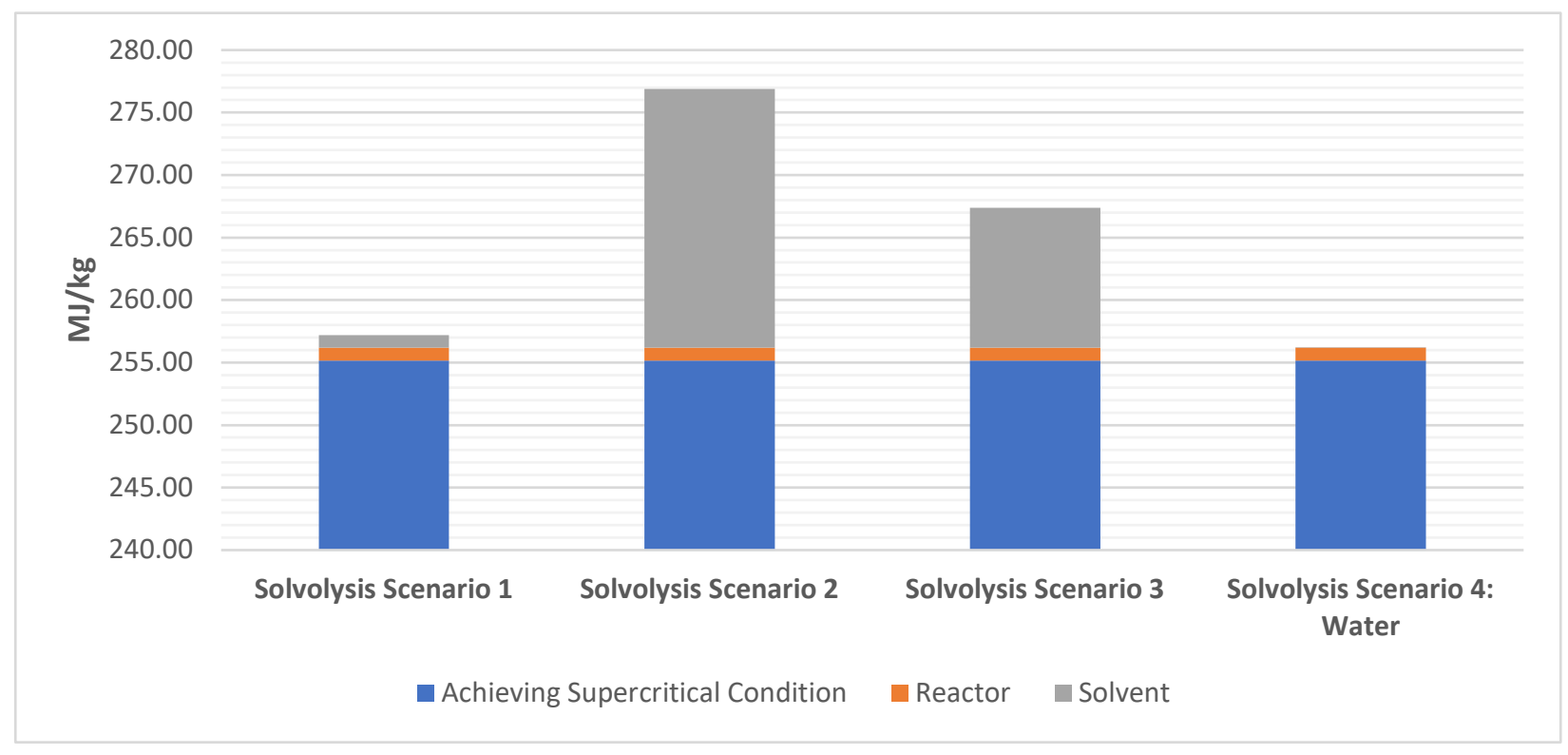

Figure 5. EE of the solvolysis process.

Table 3. Break up of EE for transportation, size reduction, and post processing.

\begin{tabular}{ccccc}
\hline $\begin{array}{c}\text { Transportation } \\
\text { EE }[\mathrm{MJ} / \mathbf{k g}]\end{array}$ & $\begin{array}{c}\text { Primary } \\
\text { Shredding EE } \\
{[\mathbf{M} / \mathbf{k g}]}\end{array}$ & $\begin{array}{c}\text { Secondary } \\
\text { Shredding EE } \\
{[\mathbf{M} / \mathbf{k g}]}\end{array}$ & $\begin{array}{c}\text { Combing EE } \\
{[\mathbf{M} / \mathbf{k g}]}\end{array}$ & $\begin{array}{c}\text { Precision } \\
\text { Cutting EE } \\
{[\mathbf{M} / \mathbf{k g}]}\end{array}$ \\
\hline 0.567 & 0.16 & 0.44 & 0.000065 & 0.000043 \\
\hline
\end{tabular}

The break-up of EE for transportation, size reduction, and post processing for Scenarios 1 to 4 is summarized in Table 4 . Total EE values for each scenario is summarized in Table 5. Similar trends as EE were also observed for cost per kg of CFRP average USD $5.20 / \mathrm{kg}$ as seen in Table 5 .

Table 4. Total EE values for each scenario.

\begin{tabular}{cccc}
\hline $\begin{array}{c}\text { Scenario 1 Total EE } \\
{[\mathrm{MJ} / \mathbf{k g}]}\end{array}$ & $\begin{array}{c}\text { Scenario 2 } \\
\text { Total EE }[\mathrm{MJ} / \mathbf{k g}]\end{array}$ & $\begin{array}{c}\text { Scenario 3 Total EE } \\
{[\mathbf{M J} / \mathbf{k g}]}\end{array}$ & $\begin{array}{c}\text { Scenario 4 Total EE } \\
{[\mathbf{M J} / \mathbf{k g}]}\end{array}$ \\
\hline 258.4 & 278.1 & 268.5 & 257.4 \\
\hline
\end{tabular}


Table 5. Breakdown of the solvolysis processing cost per kg of CFRP for the four scenarios.

\begin{tabular}{cccc}
\hline $\begin{array}{c}\text { Scenario 1 Cost } \\
\text { (USD/kg) }\end{array}$ & $\begin{array}{c}\text { Scenario 2 Cost } \\
\text { (USD/kg) }\end{array}$ & $\begin{array}{c}\text { Scenario 3 Cost } \\
\text { (USD/kg) }\end{array}$ & $\begin{array}{c}\text { Scenario 4 Cost } \\
\text { (USD/kg) }\end{array}$ \\
\hline USD 5.06 & USD 5.44 & USD 5.26 & USD 5.04 \\
\hline
\end{tabular}

The breakdown of the annual energy cost that comes from each step of the solvolysis process including the energy required to achieve supercritical condition, to power the reactor, and to add different solvents/catalysts is considered. It is to be noted that the time for such scaled-up processes will decrease based on the type of solvent used. However, due to the novel and proprietary nature of the industrial solvolysis process, this information was not provided for commercial scale facilities and, therefore, was not included in the study.

The breakdown of the processing cost per kilogram for each of the four scenarios, based on energy requirements, reveals that scenario 4 is the cheapest to produce (USD $5.04 / \mathrm{kg}$ ) and scenario 2 is the most expensive (USD 5.44/ $\mathrm{kg}$ ). There is a uniform cost of USD 5,019,000 per year to achieve supercritical condition for all four scenarios, with scenario 2 having the highest annual cost from its solvent (USD 402,500).

The EE difference between Life 1 and 2 for scenario 2 and 4, respectively, are shown in Figure $6 \mathrm{a}, \mathrm{b}$, respectively. The EE for Life 1 was higher than Life 2 for both cases, since the EE in material (CFRP and epoxy) has taken place in Life 1. The total EE for Life 1 versus Life 2 is $44 \%$ for Scenario 2 (acetone+water), and $48 \%$ lower for Scenario 4 (water), with water being lowest $\mathrm{EE}$.

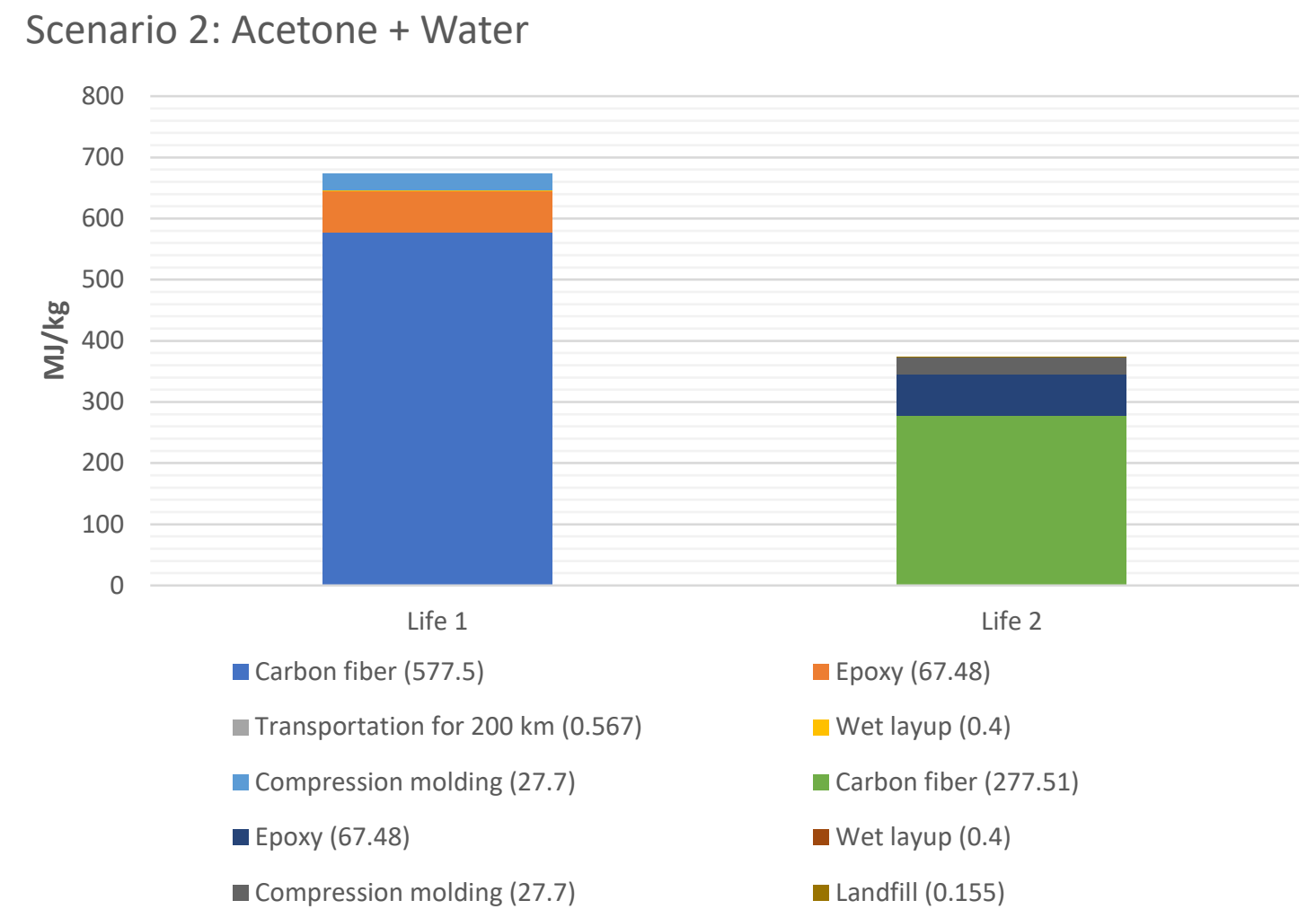

(a)

Figure 6. Cont. 


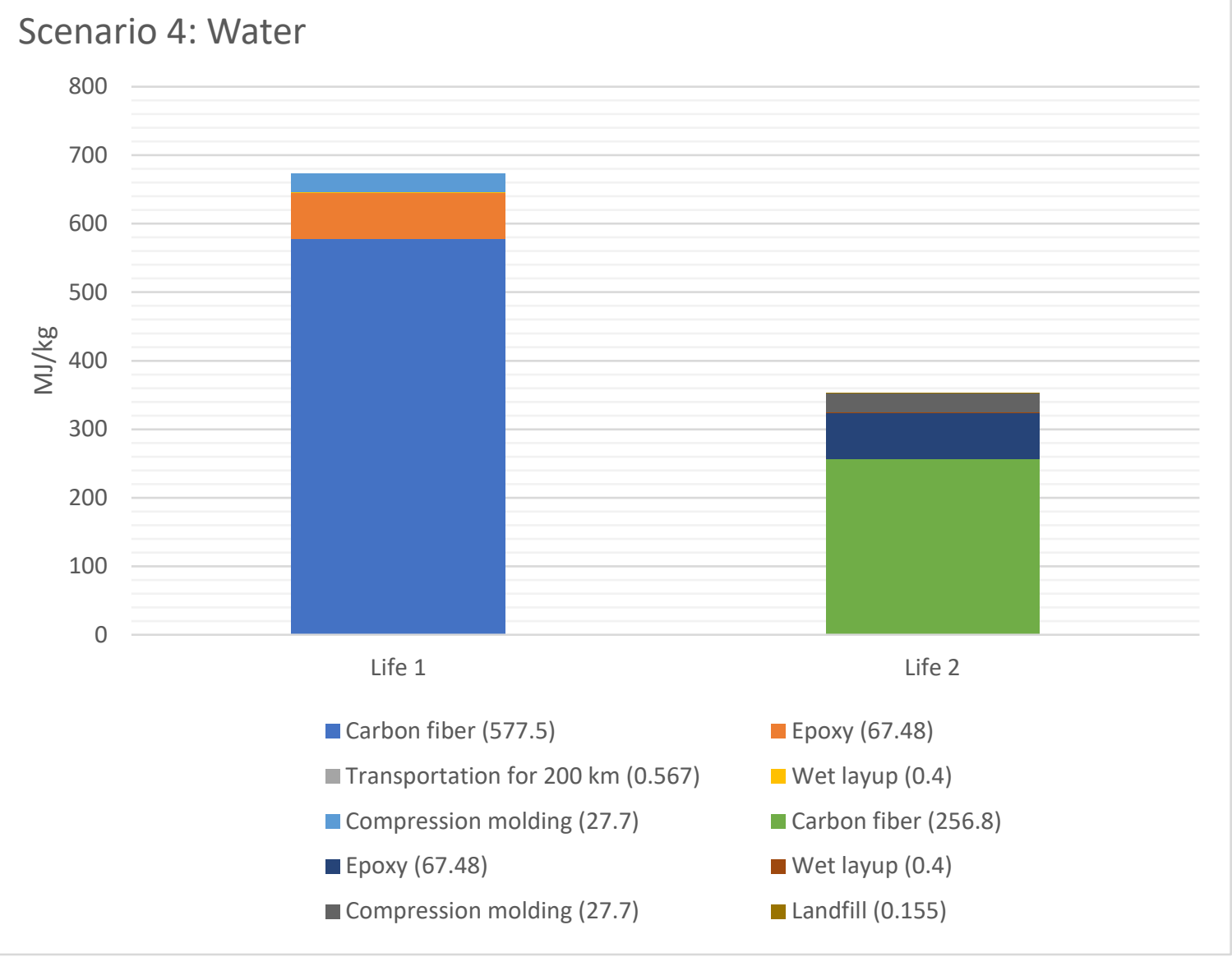

(b)

Figure 6. (a) EE difference between Life 1 and 2 for scenario 2 (acetone + water for $1 \mathrm{~kg} \mathrm{CFRP);} \mathrm{(b).} \mathrm{EE}$ difference between Life 1 and 2 for scenario 4 (water for $1 \mathrm{~kg}$ CFRP).

\section{Conclusions}

The study provided insight into a number of aspects which are summarized below:

(a) Due to the high EE of production of carbon fiber as a raw material, the EE required for conversion to recycled carbon fiber using both processes, i.e., pyrolysis and solvolysis was lower than virgin carbon fiber. The results display an overall decrease $(\sim 74 \%$ for pyrolysis and $46 \%$ for solvolysis) in EE with respect to recycled composites applying both these recycling routes;

(b) With pyrolysis, an electric furnace using renewable energy provided the lowest EE $(3 \mathrm{MJ} / \mathrm{kg}$ ) in comparison to natural gas (41 MJ $/ \mathrm{kg}$ ). However, a natural gas furnace with ability to recover syngas is more representative of current (year 2022) pyrolysis practices in industry;

(c) In the solvolysis study, only deionized water as solvent possessed the lowest EE $(257 \mathrm{MJ} / \mathrm{kg})$, whereas the process utilizing acetone and water was the most energy intensive $(278 \mathrm{MJ} / \mathrm{kg})$. The breakdown of EE scenarios in solvolysis indicates that using just deionized water (for, e.g., $150 \mathrm{~kg}$ of CFRP with $700 \mathrm{~kg}$ of water as solvent) gave the lowest EE. However, water is not always a viable option. It must be noted here that specific information regarding reaction times due to catalysts is needed for EE for solvolysis;

(d) Even with landfilling as the option for Life 2 of both scenarios, and Life 2 containing virgin resin, the EE of Life 2 drops to below half of that of Life 1;

(e) Transportation accounts for higher EE than shredding and/or secondary operations. 
(f) More research is required on (a) various furnace scenarios for pyrolysis to rank the EE, and (b) various catalysts and solvents that lessen the dwell time of the overall process, in turn reducing the cycle time and EE for solvolysis.

Author Contributions: Conceptualization, U.K.V. and S.O.; methodology, K.K.; software, K.K.; validation, U.K.V. and J.U.; formal analysis, K.K.; investigation, U.K.V., S.O., J.U. and K.K.; resources, U.K.V.; data curation, U.K.V. and K.K.; writing—original draft preparation, K.K.; writing-review and editing, U.K.V.; supervision, U.K.V. and S.O.; project administration, U.K.V.; funding acquisition, U.K.V. and S.O. All authors have read and agreed to the published version of the manuscript.

Funding: The Institute for Advanced Composites Manufacturing Innovation (IACMI) - the Composites Institute US Department of Energy, Office of Energy Efficiency and Renewable Energy, Award Number DE-EE0006926 and funding from Grant \# P42 ES027723-01A1 from the National Institute of Environmental Health Sciences (NIEHS).

Institutional Review Board Statement: Not applicable.

Informed Consent Statement: Not applicable.

Data Availability Statement: The data is available in IACMI (www.iacmi.org) archives from the technical projects under Recycling.

Acknowledgments: Contributions from 2019 IACMI summer interns Samantha Ford (Chatham University), Sabrinna Romero (Humboldt University), Isaac Sloan (Colorado State University) are gratefully acknowledged. Discussions with recycling companies are gratefully acknowledged and they are not named here, due to the proprietary nature of the energy values specific to their operations.

Conflicts of Interest: The authors declare no conflict of interest.

\section{References}

1. Brooks, A.L.; Wang, S.; Jambeck, J.R. The Chinese import ban and its impact on global plastic waste trade. Sci. Adv. 2018, 4, eaat0131. [CrossRef] [PubMed]

2. Witik, R.A.; Teuscher, R.; Michaud, V.; Ludwig, C.; Månson, J.-A.E. Carbon fibre reinforced composite waste: An environmental assessment of recycling, energy recovery and landfilling. Compos. Part A Appl. Sci. Manuf. 2013, 49, 89-99. [CrossRef]

3. Alves, S.M.C.; da Silva, F.S.; Donadon, M.V.; Garcia, R.R.; Corat, E.J. Process and characterization of reclaimed carbon fiber composites by pyrolysis and oxidation, assisted by thermal plasma to avoid pollutants emissions. J. Compos. Mater. 2018, 52, 1379-1398. [CrossRef]

4. Carberry, W. Airplane Recycling Efforts benefit boeing operators. Boeing Aero Mag. QRT 2008, 4, 6-13.

5. Wong, K.; Rudd, C.; Pickering, S.; Liu, X. Composites recycling solutions for the aviation industry. Sci. China Technol. Sci. 2017, 60, 1291-1300. [CrossRef]

6. Completing the Picture: How the Circular Economy Tackles Climate Change. 2019. Available online: https://www. ellenmacarthurfoundation.org/our-work/activities/climate-change (accessed on 2 February 2022).

7. Pimenta, S.; Pinho, S.T. Recycling carbon fibre reinforced polymers for structural applications: Technology review and market outlook. Waste Manag. 2011, 31, 378-392. [CrossRef]

8. Naqvi, S.; Prabhakara, H.M.; Bramer, E.; Dierkes, W.; Akkerman, R.; Brem, G. A critical review on recycling of end-of-life carbon fibre/glass fibre reinforced composites waste using pyrolysis towards a circular economy. Resour. Conserv. Recycl. 2018, 136, 118-129. [CrossRef]

9. Oliveux, G.; Dandy, L.O.; Leeke, G.A. Current status of recycling of fibre reinforced polymers: Review of technologies, reuse and resulting properties. Prog. Mater. Sci. 2015, 72, 61-99. [CrossRef]

10. Knight, C.C. Recycling High-Performance Carbon Fiber Reinforced Polymer Composites Using Sub-Critical and Supercritical Water. Ph.D. Thesis, Florida State University, Tallahassee, FL, USA, 2013.

11. Kooduvalli, K.; Ford, S.; Romero, S.; Sloan, I.; Coughlin, H.; Unser, J.; Vaidya, U.; Ozcan, S. Embodied Energy of Pyrolysis and Solvolysis Processes for Recycling Carbon Fiber Reinforced Polymer Waste. In SAMPE 2020 Virtual Series-Market Applications; SAMPE: Diamond Bar, CA, USA, 2020.

12. Kooduvalli, K.; Sharma, B.; Webb, E.; Vaidya, U.; Ozcan, S. Sustainability indicators for biobased product manufacturing: A systematic review. J. Sustain. Dev. 2019, 12, 55-83. [CrossRef]

13. Kooduvalli, K.; Vaidya, U.K.; Ozcan, S. Life cycle assessment of compostable coffee pods-A case study for a US university. Sci. Rep. 2020, 10, 9158. [CrossRef]

14. Morin, C.; Loppinet-Serani, A.; Cansell, F.; Aymonier, C. Near-and supercritical solvolysis of carbon fibre reinforced polymers (CFRPs) for recycling carbon fibers as a valuable resource: State of the art. J. Supercrit. Fluids 2012, 66, 232-240. [CrossRef] 
15. Prinçaud, M.; Aymonier, C.; Loppinet-Serani, A.; Perry, N.; Sonnemann, G. Environmental feasibility of the recycling of carbon fibers from CFRPs by solvolysis using supercritical water. ACS Sustain. Chem. Eng. 2014, 2, 1498-1502. [CrossRef]

16. Duda, M.; Shaw, J.S. Life cycle assessment. Society 1997, 35, 38-43. [CrossRef]

17. Morini, A.A.; Ribeiro, M.J.; Hotza, D. Early-stage materials selection based on embodied energy and carbon footprint. Mater. Des. 2019, 178, 107861. [CrossRef]

18. Composites, UK. Embodied Energy; Composites UK: Berkhamsted, UK, 2018; Volume 2017. Available online: https:/ / compositesuk. co.uk/composite-materials/faqs / embodied-energy (accessed on 2 February 2022).

19. ISO 14040. Environmental Management-Life Cycleassessment-Principles and Framework. International Organization for Standardization: Geneva, Switzerland, 2006. Available online: https://www.iso.org/standard/37456.html(accessed on 2 February 2022).

20. ISO 14044. Environmental Management-Life Cycle Assessment-Requirements and Guidelines. International Organization for Standardization: Geneva, Switzerland, 2006. Available online: https:/ / www.iso.org(accessed on 15 January 2022).

21. Wernet, G.; Bauer, C.; Steubing, B.; Reinhard, J.; Moreno-Ruiz, E.; Weidema, B. The ecoinvent database version 3 (part I): Overview and methodology. Int. J. Life Cycle Assess. 2016, 21, 1218-1230. [CrossRef]

22. Ecoinvent 3.4. 2018. Available online: https://www.ecoinvent.org/database/older-versions/ecoinvent-34/ecoinvent-34.html (accessed on 15 December 2021).

23. PRé Consultants, BV. ELCD, the European Life Cycle Database. Available online: https://simapro.com/databases/elcd/ (accessed on 5 December 2021).

24. European Commission. European Platform on Life Cycle Assessment. Available online: https://eplca.jrc.ec.europa.eu/ELCD3/ (accessed on 5 October 2021).

25. DATASMART LCI Package. Long Trail Sustainability. 2015. Available online: https://ltsexperts.com/services/software/ datasmart-life-cycle-inventory/ (accessed on 8 February 2022).

26. SimaPro. PRé. 2019. Available online: https://simapro.com/ (accessed on 4 May 2019)

27. Das, S.; Armstrong, K. FRPC Energy Use Estimation Tool; Oak Ridge National Laboratory: Oak Ridge, TN, USA, 2017. Available online: http:/ / energytoolestimator.com/ (accessed on 10 September 2021).

28. Gürzenich, D.; Mathur, J.; Bansal, N.K.; Wagner, H.-J. Cumulative energy demand for selected renewable energy technologies. Int. J. Life Cycle Assess. 1999, 4, 143-149. [CrossRef]

29. Kara, S.; Manmek, S. Composites: Calculating their Embodied Energy; The University of New South Wales: Kengiston, Australia, 2009.

30. Khalil, Y. Comparative environmental and human health evaluations of thermolysis and solvolysis recycling technologies of carbon fiber reinforced polymer waste. Waste Manag. 2018, 76, 767-778. [CrossRef]

31. Sokoli, H.U. Chemical Solvolysis as an Approach to Recycle Fibre Reinforced Thermoset Polymer Composites and Close the End-of the Life Cycle. Ph.D. Thesis, Aalborg University, Aalborg, Denmark, 2016.

32. Meng, F.; Olivetti, E.A.; Zhao, Y.; Chang, J.C.; Pickering, S.J.; McKechnie, J. Comparing life cycle energy and global warming potential of carbon fiber composite recycling technologies and waste management options. ACS Sustain. Chem. Eng. 2018, 6 , 9854-9865. [CrossRef]

33. Ekvall, T.; Tillman, A.-M. Open-loop recycling: Criteria for allocation procedures. Int. J. Life Cycle Assess. 1997, 2, 155. [CrossRef]

34. Meng, F.; McKechnie, J.; Pickering, S.J. An assessment of financial viability of recycled carbon fibre in automotive applications. Compos. Part A Appl. Sci. Manuf. 2018, 109, 207-220. [CrossRef]

35. Cunliffe, A.; Jones, N.; Williams, P. Pyrolysis of composite plastic waste. Environ. Technol. 2003, 24, 653-663. [CrossRef] [PubMed]

36. Suzuki, T.; Takahashi, J. Prediction of energy intensity of carbon fiber reinforced plastics for mass-produced passenger cars. In Proceedings of the 9th Japan International SAMPE Symposium, Tokyo, Japan, 29 November-2 December 2005; pp. 14-19.

37. Monitoring by Control Technique-Wet Scrubber For Particulate Matter. Available online: https://www.epa.gov/air-emissionsmonitoring-knowledge-base/monitoring-control-technique-wet-scrubber-particulate-matter (accessed on 10 September 2021).

38. Daniel Mussatti, P.H. Air Pollution Control Cost Manual. In Section 6: Particulate Matter Controls; Chapter 2: Wet Scrubbers for Particulate Matter; U.S. Environmental Protection Agency: Research Triangle Park, NC, USA, 2002.

39. Alibaba. 2000L High Pressure Reactor Vessel. Available online: https://www.alibaba.com/product-detail/2000L-high-pressurereactor-vessel_60500002900.html?spm=a2700.8267363.like.11.13da3e5fljJEuG (accessed on 15 October 2021). 